\title{
A importância das atividades lúdicas psicopedagógicas com crianças de 0 a 3 anos -
}

\section{uma revisão teórica}

\author{
The importance of psychopedagogical play activities with children aged 0 to 3 years - a theoretical \\ review \\ La importancia de las actividades de juego psicopedagógico con niños de 0 a 3 años: una revisión \\ teórica
}

\section{Resumo}

Este trabalho teve como objetivo pontuar a importância das atividades lúdicas para o trabalho do psicopedagogo com crianças de zero a três anos, buscando recursos para encontrar no atendimento do psicopedagogo o lúdico como formas estratégicas para desencadear o processo de intervenção na criança. O valor dos jogos e atividades lúdicas com subsídios eficazes para a construção do conhecimento realizado pela própria criança. Demonstrar a importância da inserção de jogos lúdicos, como um modelo prático de vivência e consciência, visando uma melhor prática no desenvolvimento da criança com isso os jogos são instrumentos lúdicos de aprendizagem que favorecem com eficácia proporcionando velocidade no processo de mudança de comportamento e aquisição de novos comportamentos. Assim, as intervenções com estas atividades lúdicas funcionam como diferentes meios para atingir as finalidades propostas. Buscamos a compreensão da importância dos jogos, dos brinquedos e das brincadeiras dentro do da psicopedagogia que usamos como estratégias no desenvolvimento infantil, favoráveis para o desenvolvimento cognitivo. Tendo em vista que a atuação do psicopedagogo favorecerá a criança dando um auxílio para que as situações de ensino sejam procedimentos que favorecem a compreensão no processo de aprendizagem. Tendo em vista as atividades lúdicas por meio de fantasias permanecerá no decorrer da criança em suas sessões, como principal fonte favorável para a construção de conhecimento. O psicopedagógico precisa dispor por meio de suas investigações com a criança, escola e família para buscar, reconhecer as principais necessidades para utilizar durante a realização na sua intervenção com a criança, pois utilizar-se das atividades lúdicas torna-se imprescindível na intervenção com a criança, para garantir o avanço da aprendizagem da criança, já sistematizado nesta idade.

Palavras-chave: Psicopedagogo; Intervenção; Atividades lúdicas.

\begin{abstract}
This work aimed to score the importance of recreational activities for the student's work with children from zero to three years, seeking resources to find in attendance of the student the playful as strategic ways to trigger the intervention in the child process. The value of games and fun activities with effective subsidies for the construction of the knowledge held by the child. Demonstrate the importance of inclusion of recreational games, as a practical model of life and consciousness, aiming at a best practice in the development of the child with that games are playful learning instruments favouring effectively delivering speed in the process of behavior change and the acquisition of new behaviors. Thus, interventions with these fun activities are different means to achieve the objectives proposed. We seek the understanding of the importance of the games, toys and games within the educational psychology that we use as strategies in child development, favourable for cognitive development. Since the student will foster the child giving an aid to teaching situations are procedures that favor the understanding in the learning process. Considering the activities through fantasies will remain in the course of the child in its sessions, as the main source for the
\end{abstract}


construction of knowledge. The student needs to possess through his investigations with the child, family and school to seek, recognize the main needs for use during in his speech with the child, because use of playful activities becomes essential for intervention with the child, to ensure the advancement of learning of children, already systematized at this age.

Keywords: Computers; Speech; Recreational activities.

\section{Resumen}

Este trabajo tuvo como objetivo señalar la importancia de las actividades recreativas para el trabajo del psicopedagogo con niños de cero a tres años, buscando recursos para encontrar lo lúdico en el servicio del psicopedagogo como vías estratégicas para desencadenar el proceso de intervención en el niño. El valor de los juegos y actividades lúdicas con subsidios efectivos para la construcción del conocimiento que realiza el niño. Demostrar la importancia de insertar juegos lúdicos, como modelo práctico de experiencia y conciencia, con el objetivo de una mejor práctica en el desarrollo del niño. Con esto, los juegos son herramientas de aprendizaje lúdico que promueven eficazmente la rapidez en el proceso de cambio de comportamiento y adquisición de nuevos comportamientos. Así, las intervenciones con estas actividades recreativas funcionan como diferentes medios para lograr los propósitos propuestos. Buscamos comprender la importancia de los juegos, juguetes y juegos dentro de la psicopedagogía que utilizamos como estrategias en el desarrollo infantil, favorables al desarrollo cognitivo. Teniendo en cuenta que el rol del psicopedagogo favorecerá al niño, brindándole asistencia para que las situaciones de enseñanza sean procedimientos que favorezcan la comprensión en el proceso de aprendizaje. Frente a las actividades lúdicas a través de las fantasías, permanecerá a lo largo de las sesiones del niño, como la principal fuente propicia para la construcción del conocimiento. El psicopedagogo necesita, a través de sus investigaciones con el niño, la escuela y la familia, buscar, reconocer las principales necesidades a utilizar durante su intervención con el niño, ya que el uso de actividades lúdicas se vuelve fundamental en la intervención con el niño, para asegurar el avance. del aprendizaje del niño, ya sistematizado a esta edad.

Palabras clave: Psicólogo educativo; Intervención; Actividades recreativas.

\section{Introdução}

Não é de hoje que se vê e acredita-se que o lúdico, os jogos e as brincadeiras fazem parte do desenvolvimento das crianças, tornando o cotidiano de cada uma delas, uma verdadeira etapa de desenvolvimento e aprendizado significativos, dando então um contexto histórico para as atividades lúdicas.

Segundo Santos (2001), ao longo dos séculos XVII e XVIII, os jogos foram dotando atitudes novas, pois a partir desse momento histórico passa-se a ter um novo sentimento sobre a infância, onde existem dois lados da moeda: de um lado, tem-se uma preocupação com os jogos e, do outro a preocupação para preservar sua moralidade. Tornando-se, assim, proibidos os jogos considerados maus e recomendados os jogos reconhecidos como bons. No final do século XIX, o jogo começa a ser alvo de estudos de psicólogos, psicanalistas e de pedagogos, em geral, revelando diversas teorias na busca de se compreender, cada vez melhor, o seu significado, onde a Teoria do recreio, de Schiller (1875), sustentava que o jogo servia para recrear-se, sendo esta sua finalidade intrínseca. Na teoria do descanso, de Lazarus (1883), o jogo é visto como atividade que serve para descansar e para restabelecer as energias consumidas nas atividades sérias ou úteis. Na teoria do excesso de energia, de energia excedente. Portanto, sua característica seria a de provocar catarse. Na teoria da antecipação funcional, de Groos (1902), o jogo é visto como um pré exercício de funções necessárias à vida adulta. Na teoria da recapitulação, de Stanley Hall (1906), o jogo é visto como forma de recapitular gerações passadas, caracterizando a função atávica da atividade lúdica (Santos, 2001, p.17)

Citando Santos (2001) que afirma que o lúdico não era visto como algo significativo no passado para o desenvolvimento humana e, hoje, já se faz vários estudos para entender sua distinção e buscar novas formas de favorecer as crianças, jovens e adultos da nossa sociedade. Consideravelmente os jogos, as brincadeiras e as atividades lúdicas vêm ganhando grande força nos dias atuais, fazendo com que os professores, psicólogos e psicopedagogos venham utilizá-lo em seus trabalhos com as crianças, sendo para conseguir atingir os níveis de desenvolvimento desejado ou não.

Mas mesmo mostrando o quanto é significativo cada ação lúdica, há quem diz que os mesmos não servem para nada, fazendo com que os jogos se tronem oculto perante a sociedade. Sabendo os profissionais da educação que atividade lúdica na 
infância e nos primeiros anos do processo de ensino aprendizagem traz para o convívio cultura e sociocultural do indivíduo grandes contribuições para o desenvolvimento do mesmo, deve-se fazer uma reflexão acerca dessas atividades para o planejamento pedagógico.

O psicopedagogo deve em seu desenvolvimento de trabalho levar em consideração essas atividades como meios estratégicos para abordar e trabalhar com as dificuldades de aprendizagem.

Os psicólogos contemporâneos se ocuparam em estudar os jogos e explicam-no sob dois aspectos fundamentais: "estrutura" e "conteúdo". "Na estrutura, o jogo é analisado a partir da evolução das estruturas mentais; os conteúdos são analisados a partir do desenvolvimento da humanidade" (Santos, 2001, p. 19).

Do ponto de vista da autora, as estruturas mentais são atividades realizadas pelas crianças e nem todas as atividades podem ser consideradas como jogo, pois algumas dessas atividades têm apenas uma representação simbólica. O jogo tem a existência de regras, deixam de ser um simples brincar, tornando-se jogos de competição, cooperação, liderança, garra e coragem; atividades essas como pega-pega, lenço-que-corra, esconde-esconde, entre muitas outras atividades classificadas como jogo.

\section{Metodologia}

O presente trabalho foi elaborado através de levantamento bibliográfico, de livros, revistas e artigos especializados sobre o tema. Vimos que em se tratando da psicopedagogia há ainda dúvidas que precisam ser sanadas em relação ao diagnóstico e a intervenção das crianças, e de como é importante o uso das atividades lúdicas para o trabalho psicopedagógico com crianças de zero a três anos.

Em se tratando da importância dos jogos, brinquedos e brincadeiras na psicopedagogia, vimos que esta é uma questão bastante estudada por vários estudiosos da área, dentre eles podemos citar Vygotsky, Piaget, Pain, Ferreira, dentre outros que falam como as crianças aprendem através do lúdico, de como constroem seu próprio mundo e se relacionam com ele.

Para dar sentido a esta pesquisa, nosso levantamento baseou-se na busca de informações sobre a importância do lúdico no trabalho psicopedagógico com crianças de zero a três anos, o uso dos jogos, brinquedos e brincadeiras no desenvolvimento e na construção do conhecimento. Baseados nas pesquisas bibliográficas, observamos a fala de muito dos nossos autores em relação ao uso das atividades lúdicas como forma de auxiliar no trabalho de intervenção psicopedagógica, mas não só isso, como também na parte educacional, onde a criança cria formas de se relacionar com os outros e consigo mesma dando significado a tudo que aprende.

Nessa pesquisa forma utilizados critérios básicos proposto pôr Vergara (2000), que classifica os tipos de pesquisa quanto aos fins a que se destina e quanto aos meios de investigação.

Quanto aos fins a que se destina, a pesquisa a ser realizada é do tipo descritiva e aplicada. Descritiva porque expõe características de determinada população ou de determinado fenômeno.

Aplicada porque é motivada pela necessidade de resolver problemas reais, portanto, com a finalidade prática. Quanto aos meios, a pesquisa será bibliográfica e de campo. Bibliográfica porque para a fundamentação teórico - metodológica do trabalho serão realizadas pesquisa sobre o assunto em matérias científico publicado em livros, revistas, meios eletrônicos.

\section{Resultados e Discussão}

As atividades realizadas pelas crianças são consideradas como exercício muito importante, pois, com esses exercícios a criança terá a realização e afirmação do seu "eu", sendo um processo fundamental para o desenvolvimento e aprendizagem. 
Analisando o conteúdo do jogo, Santos (2001) retrata as motivações intrapsíquicas das crianças, ou seja, é através do jogo que as crianças liberam os conflitos, eliminando-os dentro de si, absorvendo a paz interior que aquele momento o traz, tornando-se uma troca de sentimento e emoções, revitalizando o ser da criança. É possível também, perceber que a cultura as crianças trazem, pois é através das atividades lúdicas, do jogo e das brincadeiras que elas retratam sua cultura lúdica. De acordo com a autora (2001, p. 20), [...] através das atividades lúdicas a criança vai construindo seu vocabulário linguístico e psicomotor. São nesta, e provavelmente somente nestas atividades, que a criança pode ser espontânea e, consequentemente, criativa.

Muitos se perguntam, por que se jogo? Onde se joga? Quando se joga? Como se joga? São perguntas desse tipo que motivam pesquisadores a empenharem-se na busca de novas descobertas sobre o mesmo, o que nos obriga a rever uma série de conceitos sobre o jogo.

Com as grandes descobertas dos pesquisadores, surge um novo mundo "moderno", aonde os indivíduos vão cada vez mais se afastando do convívio lúdico, principalmente nas grandes cidades, impondo outras formas de lazer, como deixar de compartilhar com o outro, fazendo de seu momento de diversão, um momento individual, mas conveniente devido à vida agitada que os indivíduos têm. Com isso, acaba gerando o stress psíquico de acordo com Santos (2011). Então, assim, compreende-se que com a agitação do mundo moderno e a falta de tempo para o lazer faz com que os indivíduos deixem de praticar e ter seus momentos de ludicidade, causando um aumento das doenças psíquicas, como a depressão. Santos (2001), ainda, destacam dois tipos de lazer: lazer passivo e lazer ativo.

Na concepção de Santos (2011), o lazer passivo é quando somos espectadores e qualquer forma lúdica é realizada de forma limitada, apenas na observação das cenas assistidas; já no lazer ativo ocorre a contrário, pois é onde o indivíduo interage com os outros, com os objetos, enfim com o mundo dos demais.

Nos dias de hoje, se busca diferentes formas lúdicas, para que se possa chegar à qualidade de relação. "Quanto mais interativa for, maior será o significado que atribuiremos a ela, como maior serão, com certeza, os benefícios decorrentes dela" (Santos, 2001, p. 23).

Muitos pensadores pós-modernos acreditam que o terceiro milênio será o da ludicidade, onde surgirão novas profissões como ludólogos, ludoterapeutas, ludotecários ou brinquedistas. Na Europa, já existe formação direcionada para essa especialidade, afirma Santos (2001); em Portugal, esse especialista é denominado animador sociocultural, que atua, principalmente em escolas.

Para as definições do brincar, encontra-se vários contextos ligados às teorias, sendo que para cada teoria há uma explicação de fenômenos entre o irreal e o real que a criança pode passar em suas vivências sem se preocupar em limitar sua imaginação e criatividade.

Do ponto de vista, da teoria socia tropológica, o "brincar não é uma dinâmica interna do indivíduo, mas uma atividade dotada de uma significação social precisa que, como outras, necessita de aprendizagem” (Brougére, 2010, p.20).

O brincar consiste em um conjunto de atividades humanas, como a interpretação de uma cultura que lhe dá a posição de um desenvolvimento que requer a necessidade de aprendê-la. O sujeito está comprometido desde seu nascimento, então é através do brincar que a criança se desenvolve aprendendo e conhecendo melhor a sua cultura lúdica de origem, permitindo que o mesmo ultrapasse novos horizontes dentro do seu próprio convívio cultural, dando oportunidade de exploração do seu meio ambiente.

Brougére (2010) conclui que a cultura lúdica consiste em reproduzir a realidade, o cotidiano da criança, diferente no momento de reproduzi-la, sendo que sua estrutura não se limita a regras como num jogo de xadrez, no qual há regras precisas para se jogar. A cultura lúdica serve-se apenas de regras vagas, a exemplo da brincadeira de "papai e mamãe", que apenas permitem a organização do jogo baseada na observação de indivíduos, da realidade social para concluir sua brincadeira, ou 
seja, é a cultura lúdica que proporciona que o jogo se torne possível, que faz com que o faz-de-conta aconteça, permitindo então uma series de interpretações e entendimento do que se passa com aquele sujeito.

Com conteúdo mais precisos sobre a cultura lúdica, Brougére (2010, p. 25) diz: “[...] a cultura em que está inserida a criança é sua cultura lúdica”; onde por mais uma vez citamos que a cultura em que a criança vive, o meio-ambiente que vivencia em seu cotidiano, nada mais é que a ilustração de suas brincadeiras e jogos que por várias vezes é denominada cultura lúdica. A sociedade que transmite ao indivíduo a cultura que o cerca, faz com que o indivíduo, consequentemente, querendo ou não e até mesmo sem se dar conta reproduza a cultura de sua sociedade em suas brincadeiras e jogos de seu dia-a-dia em seu mundo lúdico, o "irreal".

A construção da cultura lúdica segundo Brougére (2010) se dá através das brincadeiras, ou seja, é brincando que a criança constrói sua cultura lúdica, onde são produzidas por um duplo movimento interno e externo, assim como comenta (Brougére, 2010, p. 26), que é o conjunto de sua experiência lúdica acumulada, começando pelas primeiras brincadeiras de bebê evocadas anteriormente, que constitui sua cultura lúdica. Essa experiencia é adquirida pela participação em jogos com os companheiros, pela observação de outras crianças [...], pela manipulação cada vez maior de objetos de jogo.

Isso significa que a cultura lúdica não se trata de algo que podemos transferir de individuo para individuo, mas de algo que é construímos desde pequeno, de recém-nascidos. Tudo o que a criança passa dentro de casa, da escola, da cidade, da rua, torna-se parte da construção da cultura lúdica do sujeito, pois, Brougére (2010, p. 27) diz: “[...] a criança vai agir em função da significação que vai dar a esses objetos, adaptando-se à reação dos outros elementos da interação, para reagir também e produzir assim novas significações [...]”. A cultura lúdica não está isolada totalmente da cultura geral da sociedade.

Segundo Brougére (2010), não é apenas o meio social que a criança vive e vivencia que defini sua cultura lúdica, ou o que ela traz desde pequeno, mas os objetos, os meios de comunicação nos dias de hoje também interferem muito dentro da cultura lúdica da criança, mas isso não significa que tudo está generalizados, se dermos o mesmo brinquedo para uma menina e um menino eles não farão as mesmas coisas com o objeto, pois, as experiências e as interações de um modo ou de outro não são iguais, a menina tem um tipo de interação com sua cultura lúdica e o menino teve outra experiência dentro da sua cultura lúdica.

Então Brougére (2010), conclui que a construção da cultura lúdica se dá por meio de suas vivencia, sejam elas: na rua, em casa, na escola ou através dos objetos, tudo interfere na cultura lúdica, tudo se relaciona de forma natural que é difícil decifrar qual momento ou objeto que trouxe à tona aquele comportamento que mostra sua verdadeira cultura lúdica.

Muitos autores como Froebel, Dewey, Brougére reconhecem a importância educativa que o jogo e as atividades lúdicas trazem. A partir dessa importância, Kishimoto (2010) vincula as relações entre o jogo infantil e a educação, com base no contexto histórico, há três concepções: a primeira é a recreação; a segunda o uso do jogo para favorecer o ensino e a educação e, por último, a terceira, que traz o diagnóstico da personalidade infantil e recursos para ajustar o ensino às necessidades infantis, mas para que conseguisse chegar a tais concepções, ele diz que os jogos eram inspecionados por homens extremamente competentes e preparados psicologicamente para que conseguissem compreender a relação dos jogos como um desenvolvimento humano. Segundo Kishimoto (2010, p. 64):

A primeira trata de recreação, onde são chamados os jogos que não exigem o esforço físico, intelectual e escolar, sendo atividades consideradas "não sérias", ou seja, atividades, que são utilizadas apenas para divertimento das crianças, são na verdade "passatempos".

A segunda concepção se entrelaça com a primeira, pois é da recreação que o educador observa a maneira com que a criança se expressa através de sua natureza psicológica. Trata-se do uso do jogo para favorecer o ensino e a educação onde, segundo Kishimoto (2010), foi durante o Renascimento que se toma a brincadeira, o jogo como algo que favorece o 
desenvolvimento da inteligência e facilita os estudos. Assim, a brincadeira é inserida nos conteúdos escolares, transmitidos às crianças de educação infantil de uma forma lúdica.

$\mathrm{Na}$ terceira e última concepção destacada por Kishimoto (2010), o diagnóstico da personalidade infantil e recursos para ajustar o ensino às necessidades infantis vêm do renascimento que se fixa com o Romantismo, pois o mesmo concretiza a criança como um ser bondoso, de uma alma de poeta, dizendo que é através do jogo que a criança se expressa, pois o romantismo vê o jogo e as brincadeiras como conduta livre, espontânea, onde se torna um instrumento para a educação infantil. "O romantismo especifica no pensamento da época um novo lugar para a criança e seu jogo, tendo como conduta espontânea, livre e instrumento de educação da primeira" (Kishimoto, 2010, p. 63).

Com essas três concepções Kishimoto (2010) afirma que o jogo veio como forma de beneficiar as crianças que o praticam, nas seguintes características: intelectual, moral e física, promovendo o desenvolvimento intelectual da criança.

Kishimoto (2010) diz que a concepção de brincadeira de Froebel, começa logo nos primeiros anos de vida de uma criança. Partindo da descoberta e do desenvolvimento de seus membros, onde a criança começa a brincar com seu corpo e seus sentidos como: mãos, dedos, lábios, língua, pés, bem como com as expressões dos olhos e face.

Dentro dessa concepção, o autor menciona que a participação da mãe é fundamental para o desenvolvimento de seus filhos. Uma vez que se interage com ele, a mesma inconscientemente contribui para o desenvolvimento da linguagem, quando conversando com seu filho, chamando-o pelo nome; ao realizar alguma atividade como trocar de roupa, ela vai descrevendo as etapas dessas atividades, por meio de perguntas como: “onde está seu braço?", “cadê seu pezinho?", "agora vamos passar a cabeça, do nenê", consequentemente esta é uma maneira prazerosa da mãe ensinar seu filho a conhecer e perceber os membros de seu corpo. O desenvolvimento da criança em seu processo escolar faz parte do auxílio de sua família, pois é a "família" que irá educar e contracenar os conflitos vividos pela criança (Kishimoto, 2010).

Percebe-se que é através das brincadeiras do dia-a-dia, que a criança tente entender o seu mundo, reproduzindo brincadeiras por meio de suas vivências, como exemplo a atitude do brincar de imitar, onde a criança utiliza-se do inconsciente para conseguir/tentar compreender o que acontece ao seu redor.

Kishimoto (2010) destaca duas definições de Froebel, sobre a brincadeira de imitar. A primeira é quando a criança se utiliza de um modelo, ou seja, a criança vê um adulto e o começa a imitar em seu mundo de faz-de-conta; a segunda se trata de imitar de uma maneira livre e espontânea, sendo ela a mais importante, pois é aqui que acontece o melhor desenvolvimento infantil: a criança tem a liberdade de imitar o que ela quiser desde fadas e duendes a monstros de conto de fadas, deixando sua imaginação ir além de suas vivencias do dia-a-dia.

Froebel (s/d) destacado por Kishimoto (2010) diz que é possível através de brincadeiras, utilizando-se de sons e ideias que se pode ensinar "linguagem", pois quando se brinca com um bebê de esconde-esconde é realizada a combinação de linguagem, regras em um contexto de umas simples brincadeiras o adulto que se interage com o bebê associa objetos com palavras, sem perceber a importância do uso de sua linguagem. Em sua teoria é perceptível a grande capacidade simbólica que a criança tem, onde ela dá significados aos objetos de seu mundo. "[...] propõe que se utilizem também as peças dos seus dons, em atividades de livre manipulação, para a recriação de objetos do mundo sensível” (Kishimoto, 2010, p.75).

Amaral (2010) cita um livro de Dewey "Escolas de amanhã", no qual o autor aborda assuntos teóricos de escolas que se esforçam de diferentes modos para dar ênfase ao crescimento lógico como instrumento de desenvolvimento de habilidades intelectuais, ou seja, por meio dos jogos as escolas pesquisadas por Dewey buscam gerar o desenvolvimento intelectual das crianças de forma natural e espontânea.

O mesmo ressalta que poucos educadores relacionam o jogo com a teoria, pois raros são os que tentaram descobrir se as atividades com os jogos podem oferecer sugestões que possam ser adotadas na escola, nem se quer pensaram em experimentas tais jogos. 
Os pequenos gostam muito de imitar os pais e os adultos que os cercam, brincando de casinha, médico, soldado, policia, entre outros, e é assim que a criança encontra o seu mundo "brincando"; retrata Amaral (2010), e enquanto estão realizando a brincadeira de imitar consequentemente adquirem os hábitos de vida da pessoa que ela utiliza para realizar a brincadeira, sendo assim se a pessoa for de má índole, resulta no aprendizado de maus hábitos e maneiras erradas de pensar e jugar.

Dewey (s/d apud Amaral, 2010) afirma que não cabe à escola impor certas ideias e hábitos nas crianças, mas é ela quem deve selecionar influências que deverão afetar as mesmas, pois sua vida social é a base de seu desenvolvimento infantil; sendo assim a escola dá oportunidade de uma social ao seu aluno. As atividades expressivas ou construtivas não são livros em cima de livros, mas atividades que dão valor no desenvolvimento da criança, pois esta visa ao descanso ou o intervalo entre uma e outra, ou seja, se preocupa com o desenvolvimento da expressão e construção da criança.

Para o autor, estudar sozinho em livros não traz o desenvolvimento de habilidades, hábitos de como agir com outras pessoas, de como controlar-se e organizar suas ações e pensamentos ou ter uma vida social desejada, pois ficar entupida de tantos livros só dará à criança a oportunidade de aprender as palavras, que não as ajudará no seu desenvolvimento de autocontrole, pois só terá o saber das palavras. Segundo Amaral (2010, p. 101),

Segundo Cerisara (2010), a fantasia está ligada ao irreal, podendo isto ser confirmado com várias situações ou acontecimentos no dia-a-dia de uma classe de crianças de 3 a 4 anos, com apresentações de um personagem, onde as crianças elevam suas fantasias ao extremo e se expressam indo além do personagem apresentado. Como foi possível chegar ao extremo da fantasia? É simples sua resposta, o irreal é formado por pequenas vivências e acontecimentos que a criança tenha passado no decorrer de sua vida.

É destaque a maneira como a criança é surpreendente com sua imaginação e criatividade diante dos textos, como é feita a combinação criadora que realiza, em determinados momentos, de frente com um personagem fictício com sua imaginação eufórica. Segundo Cerisana (2010, p. 125).

A pergunta feita anteriormente ainda requer uma resposta mais completa e sólida, onde Vygotsky ( $\mathrm{s} / \mathrm{d}$ apud Cerisara, 2010) fala de algumas das maneiras, para explicar melhor o real com a fantasia:

$1^{a}$ A criança não pode ter uma imaginação eufórica e surpreendente antes de ter vivenciado algo de sua mesma altura, ou seja, ela apenas imagina/cria através de uma realidade concreta.

$2^{a}$ A criança vivencia um fato de sua vida e em seguida reproduz sua imaginação, transformando essa vivência em algo mais elaborado em suas criações. "ouvindo-se um ponto e conta-se dois, três, quatro pontos".

$3^{a}$ Trata-se do emocional. O sentimento influencia a imaginação, ou a imaginação influencia o sentimento.

$4^{a}$ A criança é capaz de fazer da criação/imaginação uma nova criação, participa de algo novo, não existente em suas vivências, e nem uma semelhança com algum objeto.

Diante destas formas, podemos notar os grandes acontecimentos que podem ocorrer entre a realidade e a imaginação. “[...] a unidade fundamental do jogo seria a situação imaginária, na qual a criança assume o papel de outra pessoa, realiza suas ações e estabelece suas relações típicas” (Cerisana, 2010, p. 128).

Então, Cerisana (2010) conclui que a questão do despertar da imaginação, criação, faz com que a criança aprenda a lidar com as regras de maneira prazerosa, pois a criação é instinto natural da criança. Não é apenas brincar por brincar, mas sim, aprender brincando; a criança quando participa de alguma brincadeira onde ela utiliza de sua imaginação como, por exemplo, de imitar, ela se desenvolve bem melhor do que qualquer outra que não teve a oportunidade do brincar. 
O papel do Psicopedagogo, onde muitas dúvidas são identificadas, fazendo perguntas e questionamentos, "de qual é o seu papel?", “Qual sua função dentro de uma escola?”, “No que ajuda um psicopedagogo dentro da minha escola?". Com embasamentos teóricos se consegue responder essas questões, a fim de sanar as dúvidas frequentemente encontradas e questionadas, tanto pela população de pais de alunos, como também para a população no geral.

Porto (2011) apresenta o profissional como sendo um multiespecialista em aprendizagem humana, é aquele que congrega conhecimentos de diversas áreas, com a finalidade de intervir nesse processo, com sua intervenção psicopedagógica, podendo assumir uma feição preventiva ou terapêutica, relacionando-se com as equipes ligadas aos campos de saúde e educação, terapêutica e institucional, respectivamente.

Dentro da instituição escolar segundo Porto (2011), seu papel é de explicitar sobre as habilidades, conceitos e princípios que são pré-requisitos para as aprendizagens, auxiliando para que as situações de ensino sejam organizadas de acordo com a proposta de desenvolvimento adotada pela escola. É dele a função de auxiliar o professor a refletir sobre a sua prática e como articulá-la dentro da sala de aula, também participando no diagnóstico dos distúrbios específicos da aprendizagem.

Ainda a autora o psicopedagogo é aquele profissional que tem como papel principal, ser mediador, provocador de conflitos, propiciador de recursos e acima de tudo argumentador, estimulando a criança na aquisição das funções cognitivas que são pré-requisitos para as aprendizagens escolares, como também vale lembrar ainda que a profissão do psicopedagogo não é reconhecida pelos educadores como uma profissão auxiliadora de suas criança que possui uma grande importância para ajudar suas crianças a sanarem suas dificuldades de aprendizagem, ou seja, apesar de terem atribuições e competências e um código de ética sobre o nosso trabalho, ela é vista como mera auxiliadora dos problemas e déficit de aprendizagem dos alunos, e não como uma ajudar a ser dada, na valorização do desenvolvimento de suas crianças.

Para concluir Porto (2011) diz sobre o trabalho do psicopedagogo, onde cabe a ele construir o seu referencial profissional sempre em busca da teoria e da prática, seja ela na área da saúde ou da educação, mostrar a psicopedagogia como uma nova profissão e com uma nova perspectiva que visa à modificação do trabalho.

Sabe-se que muitas são as dúvidas em relação a dificuldade de aprendizagem, de como o meu aluno aprende e se ele não aprende de quem é a culpa? Então surgem muitos questionamentos sobre como diagnosticar o aluno com dificuldade de aprendizagem, de quem é o papel de diagnosticar e para onde encaminhar. Muitas dessas dúvidas e questionamentos serão respondidas neste tópico, de qual é a melhor formar de diagnosticar a criança com dificuldade de aprendizagem.

Fernández (1991) ressalta ainda que por mais que se quer a maioria dos diagnósticos utilizados pela psicopedagogia são baseados e estudados pela psicologia, e por consequência disso seus estudos ainda são dirigidos a personalidade, nossa leitura da produção desencadeada pelos mesmos surgirá da especificidade própria da atividade psicopedagógica, por isso o diagnóstico buscará responder interrogações particulares.

Segundo Fernández (1991) a resposta a esta interrogação sobre por que não aprende, não é universal. Encontramos em alguns diagnósticos explicações sobre a origem dos transtornos de aprendizagem, dentre uma delas estão os problemas de etiologia orgânicas, epilepsia, anóxia perinatal, como se a organicidade por si só determinasse e explicasse os problemas na aprendizagem. Sabemos que o organismo alterado pode provocar o alojamento de um problema de aprendizagem, mas de fato isso não é determinante.

Para a mesma autora existem outras explicações para os transtornos de aprendizagens que estão ligadas a deficiência intelectual, ou seja, pode ser um condicionante, mas não está diretamente ligado ao problema de aprendizagem. Ainda temos vistos crianças diagnosticadas como psicóticas, que não apresentam problema de aprendizagem, como também sujeitos chamados de orais que são muito bons aprendizes, e também com diferentes sintomas, não relacionados com o aprender, que cumprem uma função de equilíbrio no sistema familiar. 
Vale lembrar que a família tem papel importantíssimo dentro da aprendizagem da criança, ou seja, a princípio os pais colocam sobre a mesma grande carga de expectativas de como vai ser, o que vai fazer, com quem vai se parecer. Antes mesmo de nascer esta criança está inserida em uma constelação de significações e códigos. Por isso "não podemos entender a patologia no aprender de uma criança analisando somente o presente, fazendo unicamente um corte transversal da situação, ainda que incluamos, além do individual, o grupo familiar.” (Fernández, 1991, p.41).

O psicopedagogo como um detetive numa intervenção que observa todo o processo de aprendizagem que usa o diagnóstico psicopedagógico para detectar o problema. Sendo assim diagnóstico é uma intervenção do psicopedagogo intervindo o cliente, a família e a escola o que envolve o problema e com esse procedimento constitui em conhecimento da situação é uma compreensão a respeito do processo de aprendizagem que permite uma visão melhor para o psicopedagogo.

É de natureza multidisciplinar a atuação do psicopedagogo, tanto na clínica quanto na instituição porque na psicopedagogia possui diversos procedimentos para diagnóstico e a intervenção que recorre nas diversas áreas.

Para o psicopedagogo é de estrema valia a entrevista com a família sendo recurso para investigar vários âmbitos como o motivo da consulta; conhecer a história de vida da criança desde a gestação, realizando a anamnese, entrevistar o cliente, podendo ir até a escola ou tendo contato e outros profissionais que fazem parte do acompanhamento da criança; e da intervenção que está acontecendo encaminha aos pais e outros profissionais.

Com isso o psicopedagogo tem vários recursos para diagnostico e a intervenção. Também pode ser criativo e dar diagnóstico que possa observar os aspectos da inteligência e da projeção, que pode também encaminhar o cliente a um psicólogo com a finalidade de uma avaliação psicológica, fazendo um trabalho multidisciplinar.

A avaliação vem através de diagnósticos, onde o psicopedagogo é o mediador da avaliação tornando assim, uma avaliação assistida, segundo Porto (2011), onde o mesmo entende o processo de avaliação uma dinâmica continua atendendo as necessidades do processo ensino-aprendizagem. A avaliação dinâmica atende às necessidades do processo ensinoaprendizagem no que diz respeito ao diagnóstico e à intervenção psicopedagógica. (Porto, 2011, p.95).

Ainda a autora, não basta apenas uma avaliação assistida dentro de uma sala em que esteja o paciente e o psicopedagogo apenas, é necessário que exista uma avaliação assistida dentro da sala de aula que o paciente/aluno esteja frequentando onde o educador poderá também contribuir à avaliação.

Porto (2011), diz que são muito importantes as intervenções, dentro de quaisquer atividades humana, pois é através dela que conseguimos fazer trocas de experiências, vivencias entre outras relações, assim fazendo com que o individua consequentemente contribua com aquisição de sua aprendizagem.

Dentro da avaliação assistida, Porto (2011) ressalta que é possível avaliar as habilidades de domínio geral cognitivo, operações cognitivas e raciocínio, bem como habilidades de domínio especifico, como compreensão da leitura, consciência fonológica e habilidades aritméticas.

Concluindo com Rubinstein (1996) apud Porto (2011), onde destaca um aspecto importante dentro de uma verdadeira avaliação, dando até mesmo uma dica aos psicopedagogos já formados que estejam atuando como também para os futuros psicopedagogos que os métodos de avaliação tradicionais não são suficientes nos dias de hoje para que os mesmo consiga fazer uma avaliação real da capacidade de aprendizagem das crianças de 0 a 3 anos, ou seja, é necessário que os profissionais da área que queiram ter uma avaliação certeira, faça buscas dentro do mercado editorial, que dispõem de diversos recursos para diagnosticas e intervenção psicopedagógica, dando ao profissional psicopedagogo à desenvolver o seu trabalho de maneira eficiente e eficaz, sendo seu objetivo de trabalho preventivo ou curativo, para prevenir a instalação de problemas nos educando de 0 a 3 anos ou para intervir no problemas de aprendizagem que já esteja instalado ou que esteja se instalando na criança. 


\section{Considerações Finais}

A partir dessa pesquisa percebe-se que as crianças aprendem enquanto brincam, onde, de alguma forma a brincadeira se faz presente e acrescenta elementos indispensáveis ao relacionamento com outras pessoas; dessa forma a criança estabelece com os jogos e as brincadeiras uma relação natural e consegue extravasar suas tristezas e alegrias, angústias, entusiasmos, passividades e agressividades, é por meio da brincadeira que a criança envolve-se no jogo e partilha com o outro, se conhece e conhece o outro.

Com um olhar psicopedagógico, observamos que as interações entre as crianças em relação às atividades lúdicas compreendem em um fator determinante para a proposta desta pesquisa, ou seja, a importância do brincar como um articulador para o desenvolvimento do ser humano, de suas habilidades, capacidades, físico-motora, psicológica e sociocultural.

Em relação à epistemologia pedagógica, compreende-se que o brincar tem suas funcionalidades com o meio educacional, principalmente na Educação Infantil. Pois é na escola que a criança começa a desencadear suas potencialidades, suas vontades, e também sua aprendizagem.

E se tratando do tema proposto, a intervenção psicopedagógica engaja neste caminho; promovendo um trabalho de significação e ressignificação dos conhecimentos, possibilitando a sua apropriação, a elaboração de sentimentos e pensamentos e o resgate do prazer de aprender, descobrir, pesquisar, explorar, agir, construir, compartilhar.

Vale lembrar também que a participação da família em todo o processo do trabalho psicopedagógico é muito importante, pois é através dela é que vamos levantar informações e coletar dados, a fim de diagnosticar e realizar as devidas intervenções quando forem necessárias nas dificuldades apresentadas pela criança, não só isso, mas também pode encaminhar para outros profissionais, bem como realizar um trabalho multidisciplinar.

Conclui-se que o aspecto lúdico voltado para as crianças facilita a aprendizagem e o desenvolvimento integral nos aspectos físico, social, cultural, afetivo e cognitivo. Enfim, desenvolve o indivíduo como um todo, sendo assim, o psicopedagogo deve considerar o lúdico como parceiro na intervenção, e utilizá-lo amplamente para atuar no desenvolvimento e na aprendizagem da criança.

\section{Referências}

Amaral, M. N. de C. Dewey: jogo e filosofia da experiência democrática. In: Kishimoto, T. M. (org). O Brincar e suas teorias. 5. ed. São Paulo: Cengage Learning, 2010.

Antunes, Celso. Jogos para estimulação das múltiplas inteligências. 12. ed. Petrópolis: Vozes, 2003.

Bastos, A. B. B. I. Psicopedagogia clínica e institucional: diagnóstico e intervenção. São Paulo: Ediçõe Loyola, 2015.

Bombonatto, Q. Código de Ética da Psicopedagogia, Associação Brasileira de psicopedagogia. Psicopedagogia na Instituição de Ensino Superior, assessoramento Psicopedagógico, Artigos da Psicopedagogia Brasileira, 2008.

Bossa, N. A psicopedagogia no Brasil: contribuições a partir da prática,3 ed. Porto Alegre, Artmed, 2007- 2016

Bossa, N. Psicopedagogia: em busca do sujeito autor. São Paulo: Nadiabossa, 2000. http://nadiabossa.com.br/web/psicopedagogia-em-busca-do-sujeito

Brougére, G. A criança e a cultura lúdica. In: KISHIMOTO, T. M. (org). O Brincar e suas Teorias. 5. ed. São Paulo: Cengage Learning, 2010.

Carvalho, A. M. C. et al. (Org.). Brincadeira e cultura: viajando pelo Brasil que brinca. São Paulo: Casa do Psicólogo, 1992.

Cerisara, A. B. De como papai do céu, o coelhinho da pascoa, os anjos e o papai Noel foram viver juntos no céu! In: Kishimoto, T. M. (org). O Brincar e suas Teorias. 5. ed. São Paulo: Cengage Learning, 2010

Costa, M. L. A. D., Piaget $\quad$ A a Intervenção Psicopedagógica, São Paulo, Editora $\quad$ Olho $\quad$ D’água, 2001 . http://www.uniararas.br/revistacientifica/_documentos/art.017-2018.pdf 
Research, Society and Development, v. 11, n. 1, e5311124468, 2022

(CC BY 4.0) | ISSN 2525-3409 | DOI: http://dx.doi.org/10.33448/rsd-v11i1.24468

Freire, Paulo. Pedagogia da autonomia: saberes necessários a pratica educativa, São Paulo, Paz e Terra, 1996.

Kishimoto, T. M. Froebel e a concepção de jogo infantil. In: KISHIMOTO, T. M. (org).O Brincar e suas Teorias. 5. ed. São Paulo: Cengage Learning, 2010

Lapierre, A. A Educação Psicomotora na Escola Maternal. São Paulo, Manole LTDA, 1986.

Lomonico, C. F. Psicopedagogia teorias e práticas. São Paulo: Edicon, 1992. (Coleção Psicopedagógicas).

Novaes, Maria Helena. Psicopedagogia da educação e prática profissional. Petrópolis, RJ: Vozes, 1992.

Oliveira, V. B. (org). O brincar e a criança do nascimento aos seis anos. Petrópolis, RJ: Vozes, 2000.

Porto, Olívia. Bases da Psicopedagogia - Diagnóstico e intervenções nos problemas de aprendizagem, 5a ed. Rio de Janeiro: Wak, 2011.

Santos, S. M. P. dos (org). Brinquedoteca: a criança, o adulto e o lúdico. Petrópolis, RJ: Vozes, 2001.

Vygotsky, L. S; Luria, A. R. \& Leontiev, A. N. Linguagem, desenvolvimento e aprendizagem. São Paulo: Ícone: Editora da Universidade de São Paulo, 1998. 